\title{
Clinical judgement within the South African clinical nursing environment: A concept analysis
}

\author{
Anna C. van Graan*, Martha J.S. Williams, Magdalena P. Koen
}

School of Nursing Science, North-West University (Potchefstroom Campus), South Africa

\section{A R T I C L E I N F O}

Article history:

Received 27 April 2015

Accepted 6 May 2015

Available online 1 October 2015

Keywords:

Clinical decision-making

Critical thinking

Clinical nursing environment

Clinical reasoning

Problem-solving

\section{A B S T R A C T}

Reform in the South African healthcare and educational system were characterized by the ideals that the country needs to produce independent, critical thinkers. Nurses need to cope with diversity in a more creative way, defining their role in a complex, uncertain, rapidly changing health care environment. Quality clinical judgement is therefore imperative as an identified characteristic of newly qualified professional nurses.

The objective of this study was to explore and describe clinical judgement through various data sources and review of literature to clarify the meaning and promote a common understanding through formulating the characteristics and developing a connotative (theoretical) definition of the concept.

An explorative, descriptive qualitative design was used to discover the complexity and meaning of the phenomenon. Multiple data sources and search strategies were used, for the time frame 1982-2013. A concept analysis was used to arrive at a theoretical definition of the concept of 'clinical judgement' as a complex cognitive skill to evaluate patient needs, adaption of current treatment protocols as well as new treatment strategies, prevention of adverse side effects through being proactive rather than reactive within the clinical nursing environment.

The findings emphasized clinical judgement as skill within the clinical nursing environment, thereby improving autonomous and accountable nursing care. These findings will assist nurse leaders and clinical nurse educators in developing a teaching-learning strategy to promote clinical judgement in undergraduate nursing students, thereby contributing to the quality of nursing care.

(C) 2015 The Authors. Publishing services by Elsevier B.V. on behalf of Johannesburg University. This is an open access article under the CC BY-NC-ND license (http:// creativecommons.org/licenses/by-nc-nd/4.0/).

\section{Introduction}

Studies indicate that changes in the structure of the South African healthcare system and nursing practice complexities require nurses to have analytical and problem-solving skills so that they can make appropriate clinical decisions underpinned by holistic professional competence (OECD, 2008; Pithers \& Soden, 2000, p. 237). Fish and Twinn (1997, p. 187) emphasise that the achievement of such competence requires

\footnotetext{
* Corresponding author. School of Nursing Science, North-West University (Potchefstroom Campus), Private bag X6001, Box 520, Hoffman Street, Potchefstroom, 2520, South Africa. Tel.: +27 (0) 826869659 (mobile); fax: +27 (0) 182991827.

E-mail addresses: Anneke.VanGraan@nwu.ac.za (A.C. van Graan), Marthyna.Williams@gmail.co.za (M.J.S. Williams), Daleen.Koen@ nwu.ac.za (M.P. Koen).

Peer review under responsibility of Johannesburg University. http://dx.doi.org/10.1016/j.hsag.2015.05.003

1025-9848/@ 2015 The Authors. Publishing services by Elsevier B.V. on behalf of Johannesburg University. This is an open access article under the CC BY-NC-ND license (http://creativecommons.org/licenses/by-nc-nd/4.0/).
} 
conceptual understanding, thus allowing knowledge to be used across a variety of healthcare contexts which enables the nurse to better deal with the realities of patient care.

\subsection{Background}

Major transformation processes took place as a result of political, technological and educational reform (OECD, 2008). The South African Department of Health has been faced with enormous challenges regarding restructuring and establishing a framework for a more equitable national health system. According to the African National Congress (1994) and Geyer, Naude, and Sithole (2002, p. 11), there has been a shift from a fragmented, mainly curative, hospital-based service to an integrated, primary healthcare, community-based service. The primary healthcare (PHC) approach focuses on providing healthcare to the underprivileged, using the principles of availability, affordability, sustainability, accessibility and acceptability. The Nursing Strategy for South Africa (2008) emphasised the impact of the global shortage of nurses as well as the change of South African (SA) health service delivery which has not left nursing unscathed (Department of Health, 2008; ANC, 1994, pp. 19-20; Geyer et al., 2002, p. 11).

In South Africa the shortages are acutely felt with an estimated shortage of 44780 nurses (Daily News, 2013). The South African Nursing Council's nursing manpower-population statistics (2013) indicate that over $50 \%$ of the healthcare workers in South Africa are nurses, and that 129015 registered nurses are serving a population of 52982 000. These statistics indicate a ratio of 411 patients per one registered nurse and accentuate the fact that professional nurses are at the very core of healthcare provision. Nurses are also considered to be frontline staff in delivering safe and effective healthcare (Buchan \& Calman, 2004, p. 7; South African Nursing Council, 2013) and therefore the bulk of healthcare for patients and their families rests squarely on the shoulders of nurses (Geyer et al., 2002). The human resource crisis in healthcare is thus most felt at a nursing practice level, as nurses were demoted to primary healthcare services without the necessary preparation and support due to an increase in workload, responsibilities beyond their scope of practice, a shortage of equipment and supplies, and rapidly changing work environments (Armstrong, Geyer, Mngomezulu, Potgieter, \& Subedar, 2008; Van Rensburg \& Pelser, 2004; Walker \& Gilson, 2004).

Van Rensburg and Pelser $(2004,164)$ confirm that changes in the structure of the South African healthcare system have a number of far-reaching effects on healthcare professionals. For one, their role and function have changed dramatically from one of mainly caring for patients at their bedsides to a much wider, more demanding role. Larger sections of the population are accessing the healthcare system due to the increasing burden of more complex health problems and chronic disease (Bright, Walker, \& Bion, 2004). It can be said that South Africa is experiencing a triple burden of diseases, namely communicable diseases associated with poverty, noncommunicable diseases associated with lifestyles, and trauma and violence, most of these fuelling the HIV/AIDS epidemic. The situation is further complicated by the high unemployment rate and the influx of people into metropolitan areas. This has created an explosion of people living in squatter areas in overcrowded dwellings without basic infrastructure being provided to them, increasing the potential for health problems (Armstrong et al., 2008).

These healthcare services are publicly funded and free (treatment at all primary healthcare clinics) and available for a small fee to those able to pay (admission to public hospitals) and thus accessible to all (Geyer et al., 2002; Pelser, Ngwena, \& Summerton, 2004; Van Rensburg \& Pelser, 2004). Rendering these services requires an increase of diagnostic and curative clinical skills in the healthcare settings (Department of Health, 2008; Department of Health, 2011; Simpson \& Courtney, 2002, pp. 89-91). The legislation and introduction of remunerated community services for newly qualified nurses since 2006 led to the rotation of nurses between clinical settings in the provision of comprehensive healthcare services as required (South Africa, 2005). Nurses are thus left extremely vulnerable as they are not fully prepared, clinically or educationally, to treat patients requiring these comprehensive diagnostic and curative clinical skills due to the increase in demand as mentioned above (ANC, 1994, pp. 19-20; Department of Health, 2008; Geyer et al., 2002, p. 11).

In preparation for the professional nurse's role, undergraduate nursing students are expected to develop and integrate knowledge and practice to achieve conceptual understanding to enable them to make the necessary clinical decisions. This will have a positive impact on patient outcomes as required for competent, professional, patientcentred care. Conversely, poor clinical reasoning skills often fail to detect impending patient deterioration, resulting in a "failure-to-rescue" (Aiken, Clarke, Cheung, Sloane, \& Silber, 2003). Aiken et al. (2003) indicate this as significant when viewed against the background of increasing numbers of adverse patient outcomes. Wilson et al. (1995) found that "cognitive failure" was a factor in $57 \%$ of adverse clinical events and this involved a number of features, including failure to synthesise and act on clinical information.

In an analysis of the South African Nursing Council's (SANC, 2003-2008) professional misconduct reports, it was found that a total of 769 nurses, of which 587 were professional nurses, were found guilty of misconduct due to poor nursing care ranging from failure to properly diagnose, mistakes made during the implementation of a prescribed course of therapy, and miscommunication. It can thus be concluded that clinical decisions and judgements made by nurses in particular do not always comply with minimum expectations as reflected in the legal-ethical framework of nursing as a profession (SANC, 2008).

These expectations have been for many years part of the unique function of the nurse in assisting the individual, sick or well, in the performance of those activities the patient would perform unaided if the patient had the necessary strength, will or knowledge (Henderson, 1966, p. 15). More recently, the Royal College of Nursing (UK) has been emphasising the "use of clinical judgement", which distinguishes nursing from earlier versions (RCN, 2003, p. 3) and indicates the continuous adaptation of nursing to socio-political and cultural changes in order to meet new challenges and role requirements to enhance the quality of patient care and accountability (Ebright, Patterson, Chalko, \& Render, 2003; Fish \& Twinn, 1997, p. 184; Fonteyn, 1991; RCN, 2003; Tanner, 1998, p. 99). 
This subtle shift in focus from what nurses do to how they think about what they need to do increases the demand for higher-order and multiple thinking strategies. Strategies identified as logical reasoning, decision-making and judgement skills are thus needed at the forefront of nurses' professional identity for safe and quality clinical practice to avoid adverse events and patient harm (Benner, 1997, p. 53; Nursing Act 33 of 2005; Paul \& Elder, 2006; RCN, 2003, p. 3; Sturgeon, 2011, p. 44).

Looking at different views in the literature such as those of Alfaro-LeFevre (2012, pp. 7-8), Hoffman (2007, pp. 50-52), Phaneuf (2008, p. 2), Tanner (2006b, pp. 206-207), Thompson and Dowding (as cited in Shaban, 2005), Krairiksh and Anthony (2001) and Laurie et al. (2001), the terms clinical reasoning, problem solving, decision-making, critical thinking and clinical judgement are often used interchangeably. These terms describe the process by which nurses collect cues, process the information, reflect on, and come to an understanding of a patient problem or situation. This process is followed by planning and implementation of nursing interventions, evaluation of the outcomes, reflection on and learning from the process as well as annotations to clinical records and communications with physicians. These interchangeably used concepts can be defined as follows:

\subsection{Definition of key concepts}

\subsubsection{Critical thinking}

Critical thinking as an umbrella term includes reasoning within and outside the clinical setting. Clinical reasoning and clinical judgement are key aspects of critical thinking (AlfaroLeFevre, 2012, pp. 7-8).

\subsubsection{Clinical reasoning}

Alfaro-LeFevre (2012, pp. 7-8) refers to clinical reasoning as different ways of thinking about such patient care issues as determining, preventing and managing or teamwork and collaboration. Tanner (2006b, pp. 206-209) and Facione (2006) conceptualise it as the process by which nurses make clinical judgements as conclusions by selecting from alternatives, weighing evidence, using intuition and pattern recognition.

\subsubsection{Clinical judgement}

Clinical judgement refers to the result of clinical thinking or clinical reasoning to reach a conclusion following a process of observation, reflection and analysis of observable or available information or data (Alfaro-LeFevre, 2012, p. 8; Phaneuf, 2008, p. 1) in order to make an informed clinical decision. Thompson and Dowding (2002) and Thompson Aitken, Doran, and Dowding (2013, p. 1721) refer to clinical judgement as assessment of alternatives. For the purpose of this study, the concept of clinical judgement is the main theme under investigation and will be analysed in order to arrive at a conceptual definition to develop a clinical teaching-learning strategy to facilitate clinical judgement in undergraduate nursing students.

\subsubsection{Nurse}

Refers to a person registered in a category under section 31(1) of The Nursing Act 33 of 2005 in order to practise nursing or midwifery by caring for and treating a healthcare user (healthcare user refers to a patient and includes a male or female throughout their lifespan) to promote, maintain or restore health, and where this is not possible, cares for a healthcare user so that they can live in comfort and with dignity until death.

\subsubsection{Nursing profession}

This term refers to the context of nursing, which includes the nursing environment, nursing practice and the nurse practitioner (undergraduate nursing student). It further includes aspects of the healthcare sector, the philosophical framework of nursing in South Africa, theories of care, and the legal-ethical framework of the nursing practice, as it relates to the concept of clinical judgement (Nursing Act 33 of 2005; RCN, 2003).

\subsection{Statement of the problem}

It is thus clear that nurses need to apply higher-order cognitive thinking strategies in order to seek a broader outlook, creative solutions and multiple pathways to reach a feasible solution. Recent reforms in the South African health and educational system are characterised by the ideals that the country needs to produce independent, critical thinkers who are able to question, weigh evidence, make informed judgements and accept the incomplete nature of knowledge as well as influence change and cope with diversity in a more creative way (South Africa, 1996, p. 22; SANC, 2005). In defining their role in a complex, uncertain, rapidly changing healthcare environment, quality clinical judgement is imperative as an identified characteristic of the newly qualified professional nurse (SAQA, 2011, pp. 4-6). Despite its importance in care delivery, there is a lack of attention and research in South Africa on this issue, and international research findings are not necessarily transferable to the South African health context. In order to truly comprehend the effect it currently has in the South African clinical nursing environment, it should be recognised that there is a paucity of information on clinical judgement; and clarity on the meaning of the concept of clinical judgement should thus be sought.

\section{Research design}

\subsection{Research approach}

In this study an explorative, descriptive and qualitative design was used (Moore, 1983, pp. 205-206; 216-217; Morse, 2003, p. 833). The objective of this study was to explore and describe clinical judgement as a concept by using the eight-step process of the concept analysis method of Walker and Avant (2011, p. 160) which is based on the original method of Wilson (1963) as a method of inquiry. In this process the concept is broken down and dissected into its most basic elements through an inductive approach, so that its unique defining characteristics (attributes/connotations) can be identified, and the exact meaning of the concept clarified to result in connotative (theoretical) definitions of the concept (Walker \& Avant, 2011, p. 159-160; Burns \& Grove, 2009, p. 122). A connotative (theoretical) definition describes the "sense" of a concept, or the meaning and intention we have when we use 
Table 1 - Universal standards for trustworthiness, validity and reliability.

\begin{tabular}{ll} 
Universal standards & \multicolumn{1}{c}{ Application of trustworthiness } \\
\hline Clear definitions & Theoretical validity of the concept of clinical judgement was ensured by following these processes: \\
& - All the core characteristics of the concept "clinical judgement" were identified and reflected in a theoretical \\
& definition by a concept analysis process (Botes, 2003, p. 177; Jooste, 2010, p. 318; Knobloch, 2007, p. 31; \\
& Mouton \& Marais, 1996, p. 63; Wilson, 1963). \\
- The key concepts in the research meaning were described through the process of conceptualisation as well as & the grounding and the integration of research (Babbie \& Mouton, 2005, p. 111, Botes, 1995, pp. 11-12; \\
& Knobloch, 2007, p. 31). \\
Credibility was assured through a multi-phase literature review from which 154 definitions/uses of clinical & \\
judgement were identified. & Transferability: Data saturation occurred after analysis of 34 definitions when additional sampling provided no \\
Truth value & new information, and when themes elicited became redundant and repetitive (Burns \& Grove, 2005, p. 358). \\
Dependability was assured by stepwise replication: A step-by-step account was given of the whole research \\
process, findings and conclusions. \\
Consistency \\
- Inquiry audit: The researcher was accompanied by a promoter experienced in concept analysis research \\
which allows for achieving dependability of the data (Babbie \& Mouton, 2005, p. 278; Polit \& Hungler, 1997, p. 307). \\
Confirmability: Reached by inquiry audit as all raw data, analysis products and theoretical notes relating to \\
trustworthiness were kept to show transparency of the research process. The techniques used were the inquiry \\
audit and triangulation (discussed under credibility and dependability) (Jooste, 2010, p. 323).
\end{tabular}

the concept (Mouton \& Marais, 1996, pp. 58-59). These results serve to increase insight and understanding of the concept of clinical judgement (Burns \& Grove, 2009, p. 22; Creswell, 2005, p. 15; Morse, 2003, p. 833; Mouton \& Marais, 1996, pp. 43, 44; Polit \& Hungler, 1997, p. 20; Simmons, 2010, p. 1152).

\subsection{Research method}

\subsubsection{Study population, sampling and setting}

The population was selected from the North-West University library and included the South African journal database or SAePublications, international journal databases: EBSCOhost (Medline, Soclindex, Academic Search Premier, CINHAL, PsycINFO and ScienceDirect) and Google Scholar, books, dictionaries, thesauri, journals, theses and dissertations from the North-West University library and inter-library loans, as well as the World Wide Web. These sources were used to review the literature, including all sources in which the term "clinical judgement/clinical judgement" emerged ${ }^{1}$ (Articles N = 13 117; dissertations $\mathrm{N}=347$ and books $\mathrm{N}=146$ ).

Purposive sampling of data was done according to the stated inclusion criteria (see Table 2) and the proposed study questions. This allowed the researcher to collect rich data and gain a comprehensive understanding of the concept from various sources (Burns \& Grove, 2009, p. 352).

During the first phase of the study, dictionaries, encyclopaedias and thesauri within the disciplines of nursing, psychology and medicine were used in the concept analysis process. These sources were searched using the keyword clinical judgement/judgement.

\footnotetext{
${ }^{1}$ British English/South African English spelling of clinical judgement refers also to non-legal judgement and clinical judgment (without the e) refers to the American English spelling and legal judgment.
}

This process yielded $\mathrm{N}=154$ dictionary/encyclopaedia publications to further reduce the volume publications to $\mathrm{n}=24$ with adjustments for double entries and no definitions.

Sample size. The number of literature sources sampled was determined by the depth of information needed to describe the concept of clinical judgement, and to achieve saturation of information (Burns \& Grove, 2009, p. 361).

The second phase included a multistage search and the World Wide Web, books, theses, dissertations and journals were used to provide an integrative literature review to confirm the findings of the concept analysis (see Fig. 1). They were searched using the keyword clinical judgement or clinical judgement and nurs* included in the title or abstract was retrieved, yielding a total of 13464 publications. Due to the volume of the data retrieved, additional limits were placed and the following criteria as indicated in Table 2 were set.

A strict record was kept of each step of the sampling process and detailed information documented on each source used so that the researcher's decisions and study results could be trailed and evaluated if required (Walker \& Avant, 2011). The process that was followed by the researcher in the study during the integrative literature review (phase 2 of the study) is outlined in Fig. 1.

\subsubsection{Data collection}

The data collection techniques are illustrated and explained in the steps of the concept analysis process of Walker and Avant (2011) in order to clarify the contribution of the different methods to the understanding of the concept of clinical judgement as applied in this study.

\subsubsection{Rigour}

Rigour is the umbrella term used to encompass all strategies, namely trustworthiness, validity and reliability as indicated in Table 1. 
Table 2 - Concept analysis search criteria.

Inclusion criteria

Exclusion criteria

- The language of the data must be English to allow understanding of the text - Editorials

- Letters to the editor

- Within the nursing context.

- Book reviews

- The articles must be peer-reviewed.

- The articles have to be published within the timeframe of January 1982 (when the scientific nursing process with focus on critical thinking and judgement was refined and applied in various health services) until June 2013 (time of data collection).

- Commentaries

- Papers with subject terms related to legal and financial concepts were filtered out of the search, as the researcher only wanted to use those definitions or descriptions of clinical judgement related to care giving/nursing care to people in a clinical health care environment.

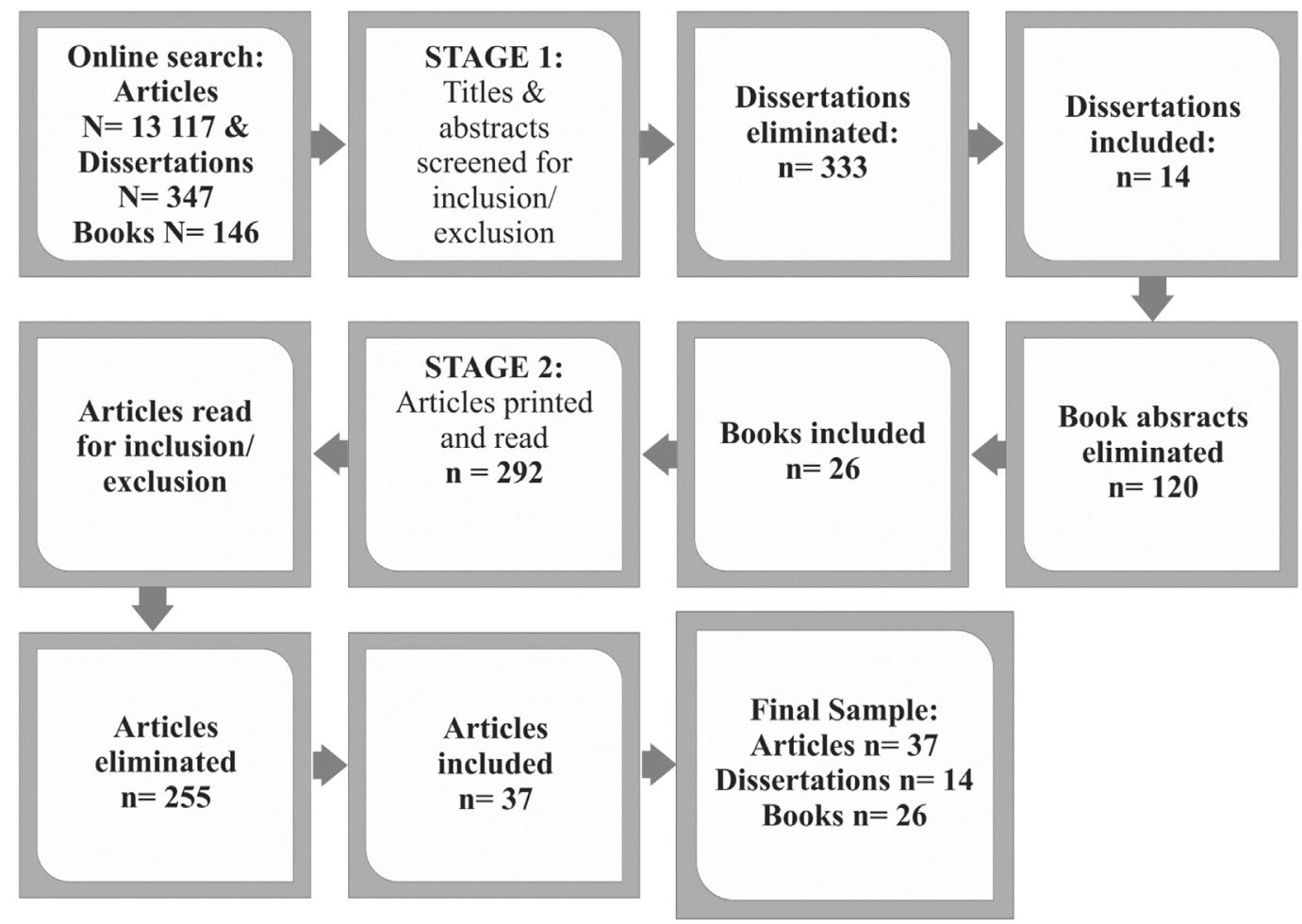

Fig. 1 - Integrative literature review strategy.

\subsubsection{Ethical considerations}

Ethical permission was obtained from the North-West University ethics committee (NWU-00107-13-S1) as well as research experts who also scrutinised the research proposal during a formal public defence.

\section{Findings \& discussion}

\subsection{Results}

Step 1: Selecting a concept

The selected concept was of interest to the researcher as clinical judgement is a complex and relatively confusing term which is often used interchangeably with the terms clinical reasoning, problem solving, decision-making and critical thinking. Clinical judgement is viewed as an essential cognitive nursing skill and has become synonymous with the scientific nursing process model of nursing practice as a problem-solving activity (Tanner, 2006b, p. 204). Clinical judgement is tremendously complex and changes over time. The cultural and nursing complexities of South Africa contribute to possible changes. Providing competent individualised nursing care is thus crucial and therefore conceptualisation of the phenomenon is necessary (Walker \& Avant, 2011, p. 160). On the basis of the identified problem, clinical judgement was chosen as the central concept.

Step 2: Determining the aims of analysis

Walker and Avant (2011, p. 161) acknowledge that a concept analysis should never be considered as a finished product, but rather as a work-in-progress as concepts change over time. In this study the concept analysis aimed to promote a common understanding and to clarify the meaning of clinical judgement by formulating the characteristics and developing a 
connotative (theoretical) definition. This analysis will therefore add to the existing theory of the concept, as clinical judgement is an essential component of clinical/professional competence and moral development. These findings will assist nurse leaders and clinical nurse educators in supporting undergraduate nursing students to develop clinical judgement and effective reasoning thereby contributing to the quality of healthcare (Walker \& Avant, 2011, p. 161; Furguson, 2006, p. 2).

\section{Step 3: Identifying all uses of the concept}

Clinical judgement is used interchangeably with higherorder cognitive skills such as decision-making, critical thinking and clinical reasoning, and mostly appears in subject dictionaries and scientific literature sources. Due to the use of the British English spelling (clinical judgement) in South Africa, the American English spelling (clinical judgement) of the concept was also used (see footnote). The common uses of the word clinical judgement and clinical judgement were explored during this first phase of the study. Data collection involved using dictionary, thesauri, subject dictionaries and encyclopaedic definitions as well as descriptions from scientific literature sources from the North-West University library and the World Wide Web (see Table 2). Psychology, nursing and medical dictionaries were used to limit bias in the understanding of the concept (Burns \& Grove, 2009, pp. 355-356; Walker \& Avant, 2011, pp. 161-162).

For this research, 34 of the definitions/uses of clinical judgement were identified and documented. Clinical judgement as a concept is difficult to define as evidenced by the various definitions found in the literature. In the following section excerpts of the standard dictionary definitions and the sourced literature definitions will be discussed.

\subsection{Conceptualising clinical judgement in healthcare}

Standard dictionary definitions provided a conceptual starting point. According to the Miller-Keane Encyclopaedia and Dictionary of Medicine, Nursing, and Allied Health (2003), clinical judgement is the process by which the nurse decides on data to be collected about a client, makes an interpretation on the data, arrives at a nursing diagnosis and identifies appropriate nursing actions. This involves problem solving, decision making and critical thinking.

Miller-Keane Encyclopaedia and Dictionary of Medicine, Nursing, and Allied Health (2003) together with Mosby's Medical, Nursing and Allied Health Dictionary (1998) and Mosby's Medical Dictionary for the Health Professions and Nursing (2012) focus in their definitions on the critical decisions that are made on the basis of scientific observations but with the added skill provided by long experience of similar cases. To this must be added an instinctive ability to make balanced judgements based not only on the state of the patient and their anticipated future but also on some consideration for the patient's overall well-being and the client's financial status and degree of psychological or, in some cases, actual dependence on the patient. The Medical Dictionary for Health Professionals and Nursing (2012) supported by Sque, Chipulu, and McGonigle (2009, p. 236) indicates that a cognitive or thinking process is used for analysing data-deriving diagnosis, deciding on diagnosis and evaluating care. The application of information is based on actual observation of a patient, combined with laboratory findings and the healthcare workers' training and experience in determining a diagnosis. Mosby's Medical Dictionary for the Health Professions and Nursing (2012) highlights the ability to recognise the relationship of ideas and to form correct conclusions from the data as well as from experience.

A review of the literature enabled the researcher to determine the defining attributes of clinical judgement and, according to Walker and Avant (2011, p. 160), the heart of concept analysis. The most often cited author related to clinical judgement is Christine Tanner (2006) who describes clinical judgement as a flexible and nuanced ability to recognise salient aspects of an undefined clinical situation, interpret their meanings and uses pathophysiological and diagnostically aspects of a patient's clinical presentation of disease and illness experience (Tanner, 2006b, p. 204). Tanner (2006b, p. 208) furthermore believes there are four dimensions in clinical judgement, namely noticing, interpreting, responding and reflecting.

The level of ability a nurse uses to engage in effective noticing varies with the context, the nurse's background and the nurse's relationship with the patient. Clinical reasoning and clinical judgement are reciprocal, and clinical reasoning informs judgement, which informs reasoning, while critical thinking is foundational to both. The use of the intellect is also confirmed by Le Grant Robbert (as cited in Phaneuf, 2008, p. 1). Tanner further describes clinical judgement as an interpretation or conclusion about a patient's needs, concerns or health problems and/or the decision to take action (or not), use or modify standard approaches as a flexible and distinct ability to recognise salient aspects of an undefined clinical situation, to interpret their meanings, and respond appropriately (Tanner, 2006b, p. 204). Nissen (1884, p. 132) highlights the moral dimension as the nurse must seek to place herself in the patient's place.

\subsection{Connotative (theoretical) definition of clinical judgement}

The meaning of the concept of clinical judgement was synthesised from the characteristics of clinical judgement (see Table 3 for quantification of characteristics). The connotative (theoretical) definition of the concept of clinical judgement in this study is based on the information gained from the process of Walker and Avant (2011, pp. 162-163):

Clinical judgement is the conclusion at which a nurse arrives through the ability to recognize salient pieces of information gathered by direct observation and patient assessment within an undefined clinical context. Interpretation of meaning is followed by a period of reflection, and reasoning across time to come to a clinical grasp/ informed opinion of the situation. Appropriate response to the identified salient aspects is based on empirical knowledge, shaped by the nurse's clinical experience, intuition and ethical-moral beliefs as to solve the patient's nursing care problems as outcome. 


\section{Table 3 - The characteristics (attributes) most commonly associated with the concept of clinical judgement.}

Characteristics (attributes) of the concept of clinical judgement

antification of

characteristics according to use

Defining characteristics of clinical judgement clustered according to synonyms

$1,3,7,14,15,20,21,24,34$

- Informed decision making/informed opinion/enlightened opinion/clear opinion/come to a conclusion/outcome/ decision/inference/differential nursing diagnosis, choice between alternatives

2 Actual patient observation/subjective and objective data

3 Nuanced/distinct ability

4 Recognise salient aspects within the context

5 Reasoning across time

6 Managing uncertainty

7 Empirical knowledge

8 Interpretation of meanings

9 Nurse's background

10 Multi-layered problems

11 Outcome of reasoning

12 Contextual decision- making from critical thinking

13 Come to a conclusion of critical thinking/inference

14 Application of clinical knowledge

15 Assessment of the clinical situation/ patient assessment/clinical presentation of disease

16 Evidence-based outcome

17 Reflection (in, on, beyond)

18 Prioritising of data
$1,7,14,20,23,24,25,29,31$ - Data gathering/observing/assessment/noticing/recognise

- Contextual/undefined clinical situation/manage uncertainty/ undefined clinical situation

$2,9,16,17,19,20,24,28,31,33$ - Reasoning over time/future thinking/predictions of future behaviour

\section{$3,4,7,8,20,28,34$}

$2,15,19,20,22,26$

$2,7,13,15,20$

2, 4, 9, 11, 16, 20, 23, 24, 28, 32 • Problem solving:

- Appropriate nursing actions/appropriate involved way/

5 - Clinical grasp

$11,16,19,20$

- Assessment of alternative meanings in healthcare setting

- Nurses' beliefs

- Based on ethical and moral decision-making

$2,6,7,13,15,19,29,31,20$

$1,2,19,6,2124,27,33,34,35$

- Patient/clinical proficient/expertise performance/intuitive response
$3,9,14,20,21,25,28,33,32$

- Clinical knowledge/clinical experience/practice/added skill/
11,15

$7,14,20,36$
Defining characteristics

of clinical judgement as used for theoretical definition

Informed opinion

- Clinical context

- Clinical experience

- Conclusion

- Undefined context

- Patient assessment

- Actual patient observation

- Interpretation of meaning

- Empirical knowledge

- Reasoning across time

- Identify and evaluation of

alternative options

- Critical thinking

- Reflective thinking (in action)

- Recognition of salient aspects

CONCEQUENCES • Intuition

- Nurses' beliefs

- Reflective thinking

(on action, beyond)

- Appropriate response

- Outcome

- Problem solving

- Decision-making

(choose between alternatives) 


\subsection{Identifying a model case}

The following model case using a nursing example was constructed to demonstrate all the defining characteristics of clinical judgement in order to provide insight into the internal structure of the concept and allow clarification of its meaning and context (Walker \& Avant, 2011, p. 163).

Susan, a senior nurse, works in the surgical ICU and has ten years of clinical experience. She has just received the progress report from the night shift regarding Mr Beukes; she was briefed about his health history, with a diagnosis of cancer of the larynx and that he had radical neck dissection surgery the day before. Mr Beukes has a tracheotomy in situ and requires frequent suctioning for excessive secretions. He is alert and responds by nodding his head. When Susan enters the room to change the infuse pump and administer the antibiotics, she gathers salient pieces of information by observing, listening and attending to what is happening. Susan comes to an informed opinion of Mr Beukes and sees that he needs a nurse and nursing care, is apprehensive and tachypneic and has an esturing response for her to come into the room. Susan's clinical constructions vary with the events that unfold as she senses the situation and responds sensitively as shaped by her ethical-moral beliefs to the changing circumstances as she is in the role of comforter. Susan uses reflection in action while systematically assessing his multi-layered problems by auscultating the lungs and observing salient data of coarse crackles and expiratory wheezes. Thick secretions are bubbling out of his tracheotomy, with a poor cough effort. She discovered this when looking for a pattern of behaviour by connecting seemingly unrelated pieces of information. On the basis of these salient data, she reasons across time and engages through use of reflection on action in all these activities by drawing a valid conclusion of ineffective airway clearance as nursing diagnosis. As Susan collaborates with the patient she explains to Mr Beukes and his wife that the accumulated secretions impair the airway which is leading to the difficulty in breathing and tracheal suctioning. Suctioning will be the treatment of choice to improve his breathing. Mrs Beukes enters into dialogue with Susan and asks if she is going to inject water into the tube during the procedure. Susan recalls clinical knowledge and replies that the use of saline is not according to best practice guidelines due to the high risk of fluid accumulation in the lungs, choking, and infection as complications. Mrs Beukes responds with relief and gains trust during Susan's demonstration of competence. During the procedure Susan observes the patient's non-verbal pattern of response and notes that he is less apprehensive on completion of the suctioning. By reflection on action she auscultates the lungs and notes decreased crackles and expiratory wheezes but senses a rapid irregular pulse rate as well as severe peripheral cyanosis. As she has experience of similar situations, she realises the limitations of her experience and responds to the uncertainty of the situation. Susan rings the bell for assistance, while giving three direct ambubag inhalations followed by $100 \%$ oxygen by a polymask to increase his saturation. A few minutes later Mr Beukes smiles and indicates that his breathing has improved.

\subsection{Identifying additional cases}

In this study use was made of a borderline case and a contrary case. Identification of these two cases allowed the researcher to distinguish between concepts that are similar to and contrary to clinical judgement (Walker \& Avant, 2011, p. 164). The borderline case of clinical decision-making was chosen as judgements and decisions are closely related, and both elements are claimed throughout the literature to contribute to the appropriateness of nurses' eventual actions. Although there are similarities to clinical judgement as an attribute of decision-making in many ways, there are characteristics that differ significantly between the two concepts (Thompson \& Dowding, 2009, p. 5; Thomas, Wearing, \& Bennett, 1991, as cited in Smith, Higgs, \& Ellis, 2006, p. 89). Clinical decisionmaking and clinical judgement are both identified as interrelated cognitive thought processes. A study by Scott et al. (1999, p. 10) has highlighted the contribution of skilled nursing care to patient outcomes. One of the factors that mark out exceptional nurses is their skill in judgement and decision-making.

Decision-making is similar to clinical judgement in that it shares the following characteristics: contact with patients, clinical experience, clinical context, clinical engagement, clinical reasoning, clinical grasp, contextual decision-making and associated nursing action. Although clinical judgement is an attribute of decision-making and decision-making a consequence of clinical judgement, both elements contribute to the appropriateness of the nurse's eventual actions and nursing care outcomes. Furthermore, a nurse might make an accurate judgement based on information but then go on to choose inappropriate action or decision. Alternatively, a nurse might make a poor judgement and go on to make a good decision on the basis of the poor judgement made. The borderline case will be defined as follows:

\subsection{Clinical decision-making is comprehensively defined as follows}

Making clear choices which produce an outcome - as an action to do or not to do between limited options in dynamic contexts/situations of change and uncertainty using a diverse knowledge base (body of evidence-based literature), a grouping of reasoning techniques accompanied by experience with multiple variables and individuals involved. Decisions are embedded in a decision-action cycle, cover elements of time pressure, individual stress in a process of collaboration involving collective and parallel decision-making with individual patients, family and the multidisciplinary health team, within the organisational goals and norms of professional nursing practice (Dowie, 1993, as cited in Thompson \& Dowding, 2009, p. 3; Edwards, Jones, Higgs, Trede, \& Jensen, 2004; Patel, Kaufman, \& Magder, 1996, as cited in Smith et al., 2006, pp. 89-90; Thomas et al., 1991 as cited in Smith 
et al., 2006, p. 89). The contrary case, as opposite to clinical judgement, is discussed next.

\subsection{Contrary case}

A contrary case aims to give an example of what the concept of clinical judgement is not (Walker \& Avant, 2011, p. 166). In this study, the concept of judgement error is described as the opposite extreme or example of what clinical judgement is not. Although no formal definition of poor clinical judgement/ inaccurate judgement or judgement error was identified in the literature review, aspects as discussed by Sari et al. (2007, p. 436) and Thompson and Dowding (2009, pp. 93-96) explained errors and mistakes as any unintended event caused by the healthcare provider that either did or could have led to patient harm (Sari et al., 2007, p. 436) as a result of such incidents which are known as adverse events or patient safety incidents.

Therefore clinical judgement mistakes happen when our reasoning goes awry and our intended actions do not proceed as planned and fail to achieve our immediate goals or intended outcome and when these failures cannot be attributed to the intervention of some change agency (Reason, 1990 as cited in Thompson \& Dowding, 2009, pp. 93-96). Failures can be due to an error of omission (absence of knowledge for accurate assessment) and/or error of commission (the knowledge was there, but not used correctly). The characteristics of this comprehensive definition in the contrary case are illustrated below:

As a nurse you are assisting Mr Broom, a 68 year-old man with chronic obstructive airway disease (COPD), with a bed bath for personal hygiene. You notice while assisting with the wash that the patient appears cyanotic and is gasping for air and you decide to give him some oxygen at $35 \%$. In your experience, oxygen helps with breathlessness and so you consider this to be a sensible intervention. You reflect in action and remember that in the past people you cared for responded well on oxygen therapy. After $15 \mathrm{~min}$ you check on the patient and notice that he is breathing more rapidly. You respond with ignorance to the patient's request to help him to relieve his breathlessness. You adjust the oxygen to $65 \%$ and change the nose cannula, to a poly mask. After $30 \mathrm{~min}$ you visit the patient again and observe that he is breathing rapidly and his oxygen saturation has dropped rather than improving. As you are an experienced nurse, you didn't apply logic and did not realise that in healthy people, the respiratory drive is largely initiated by PCO2 but that in COPD, hypoxia on its own is a driving force for breathing and if hypoxia is corrected the expiratory drive will be reduced. Two hours later Mr Brook is transferred to the ICU as he needs respiratory assistance.

This example of a contrary case indicates how the situation reflects the mistakes in the nurse's reasoning ability where knowledge and critical thinking for accurate assessment was missing and the knowledge that was available was not used correctly during the application of oxygen to the patient with hypoxia and chronic obstructive pulmonary disease (COPD).
The nurse's intended actions didn't proceed as planned and failed to achieve the outcome, with the result that the respiratory drive was reduced and hypoxia developed as an adverse event resulting in patient harm.

\section{Conclusion \& recommendations}

The objective of this study was to explore and describe clinical judgement as a concept and to promote a common understanding by clearly explicating and clarifying the meaning. To realise this objective, a concept analysis was performed using the method of Walker and Avant (2011), based on the original method of Wilson (1963).

The relevance of this study is evidenced by the fact that it is the first South African study to synthesise a connotative (theoretical) definition of clinical judgement with specific reference to the clinical nursing environment. The findings demonstrate the use and importance of clinical judgement as a cognitive skill in the clinical nursing environment. This concept analysis will contribute to a better understanding of the concept in nursing practice and theory, and can thereby improve autonomous and accountable nursing care as clinical judgment is an essential component of clinical/professional competence and moral development. These findings will assist nurse leaders and clinical nurse educators in developing a teaching-learning strategy for supporting undergraduate nursing students to develop and implement clinical judgement skills which will in turn contribute to the quality of healthcare in South Africa (Walker \& Avant, 2011, p. 161; Furguson, 2006, p. 2).

\subsection{Discussion of the study results}

The purpose of this analysis was to define the concept of clinical judgement by means of a literature study across some key disciplines. The meaning of clinical judgement was clarified through using the eight steps of Walker and Avant (2011). Antecedents of clinical judgement were indicated as informed opinion, clinical context, clinical experience, conclusion, undefined context, patient assessment, actual patient observation, interpretation of meaning, empirical knowledge, reasoning across time, identification and evaluation of alternative options, critical thinking, reflective thinking (reflection in action), recognition of salient aspects, intuition and nurses' beliefs. The consequences of clinical judgement were reflective thinking (reflection on action and reflection beyond), appropriate response, outcome, problem solving, and decision-making (choosing between alternatives).

\subsection{Theoretical definition of clinical judgement}

It is difficult to establish one, single definitive definition for clinical judgement, a concept which is critical to the nursing profession because of its outcomes. Many authors have come up with thoughtful definitions as mentioned, but clinical judgement is very complex due to the prior training required, and experienced nurses need to develop a deep understanding of the subject. Therefore simplicity is required to grasp this concept. The identified attributes as supported by the 
literature have quite significant similarity with the clinical judgement models of Phaneuf's formulated clinical judgement process and Tanner's research-based model of clinical judgement in nursing (Phaneuf, 2008 p. 1; Tanner, 2006b, pp. 204-2011).

The following discussion points out the importance of the identified characteristics of the theoretical definition as formulated from this research and will be demonstrated through the resemblance to the characteristics of clinical judgement as defined by Phaneuf (2008) and Tanner (2006b).

\subsection{Observation, assessment, salient pieces of information}

According to Phaneuf (2008, pp. 1-2), clinical judgement depends on the nurse's ability to observe and to identify relevant information. Tanner's (2006b) four-phase model illustrates noticing, which involves focused observation, information seeking and recognising deviations from expected patterns and this research study indicates "recognise salient pieces of information gathered by observation and assessment."

\subsubsection{Explanation of meaning}

Observation/assessment and noticing include a variety of objective and subjective data to uncover full/important information regarding the patient and his/her circumstances (Benner, Tanner, \& Chesla, 2009, p. 387; Frith \& Clark, 2013, p. 112; Gotlieb, 2013, p. 205; Higgs, Jones, Loftus, \& Christen, 2008, p. 27; Lasater, 2007, p. 497; Standing, 2008, p. 13).

\subsection{Interpretation, reasoning, prioritising of data,} identifying patterns, clinical grasp/informed opinion

Phaneuf (2008) accentuates reasoning as a tool to associate pieces of information and to review them to establish relationships with known facts to analyse through the use of critical thinking and interpret the data at hand. The second concept in Tanner's (2006b) model illustrates interpretation, which involves prioritising data and making sense of data by the identification of patterns through different reasoning patterns such as analytic, intuition and narrative reasoning. In this study the characteristics of interpretation of meaning, a period of reflection, and reasoning across time to come to a clinical grasp/informed opinion of the situation were identified.

\subsubsection{Explanation of meaning}

Prioritising data: Focus on the most relevant and important data useful to explain the patient's condition. Interpretation: Make sense of data. Reasoning is the cognitive process of using critical thinking to interpret a situation. Identifying of patterns: Looking for patterns in the patient's data and comparing with known patterns from knowledge, intuition and experience. Clinical grasp/informed opinion: Through experience to combine salient pattern recognition and trigger an established response through developing knowledge and repeated exposure. It includes problem recognition and clinical judgement over time (Alfaro-LeFevre, 2012, pp. 7-12, p. 70; Simmons, 2010, p. 1155; Benner et al., 2009, pp. 16, 387; Facione
\& Facione, 2008b, pp. 3-4; Higgs et al., 2008, pp. 5, 7; Lasater, 2007, p. 497; Masters, 2005, pp. 85, 91, 92; Ebright et al., 2003, as cited in Frith \& Clark, 2013, p.113; Teekman, 2000, pp. 1127-1128; Bandman \& Bandman, 1988, pp. 85-86).

\subsection{Response and reflection}

\subsubsection{Explanation of meaning}

Appropriate response is indicated by Tanner (2006b, p. 205) to be a concept of importance and in this study indicates interventions tailored for the individual patient, monitoring the patient's progress closely and adjusting treatment as indicated by the patient's response.

Reflection involves reflection-in-action during interpretation of data and reflection-on-action about the appropriateness of the course of action (Cotton, 2001; Frith \& Clark, 2013, pp. 112-113; Higgs et al., 2008, p. 6; Masters, 2005, p. 94; Standing, 2011a, pp. 106; 122; Schön, 1987, as cited in Lasater, 2007, p. 497).

\subsection{Context of uncertainty, practical experience, theoretical knowledge, intuitive knowledge, ethical perspectives and relationship with the patient}

According to the clinical judgement models of Tanner (2006b) and Phaneuf (2008), the nurse's perception of any situation is shaped by the context of uncertainty, practical experience and is rooted in the nurse's theoretical knowledge, intuitive knowledge, ethical perspectives and relationship with the patient.

\subsubsection{Explanation of meaning}

Practical experience refers to knowledge gained from previous clinical situations; context of uncertainty includes the continuously changing clinical (patient) situation; intuitive knowledge refers to the sense of immediate knowing of objective patient data, and defined as a clinical grasp of ambiguous patterns of patient data (Benner, HooperKyriakidis, \& Stannard, 1999, as cited in Minick \& Harvey, 2003, p. 292; Erickson et al. 2007, p. 62). Theoretical knowledge is knowledge based on evidence (Alfaro-LeFevre, 2012, pp. 10, 54, 75, 96; Benner et al., 2009, pp. 16, 387; Facione \& Facione, 2008b, pp. 2-4; Higgs et al., 2008, pp. 9, 12, 140; Le Grant Robbert, as cited in Phaneuf, 2008, p. 1; Lasater, 2007, p. 497; Masters, 2005, p. 117; Melnyk \& Fineout-Overholt, 2005, pp. 170-177; Nojima, Tomikwa, Makabe, \& Snyder, 2003, p. 9; Hammond, 1996a, 1996b, p. 86; Benner, Tanner, \& Chesla, 1992, p. 20; Dewey, 1987 , p. 100).

Critical thinking for nurses is therefore defined by authors Bitter and Tobin (1998, p. 269) and Scheffer and Rubenfeld (2000, p. 357) as being influenced by knowledge and experience, using strategies such as reflective thinking to holistically synthesise patient information in the nursing practice and is thus an essential component of professional accountability and quality nursing care. Nurses with critical thinking skills exhibit confidence, contextual perspective, creativity, flexibility, inquisitiveness, intuition and reflection making use of cognitive skills such as analysing, reasoning, predicting, information seeking and transforming knowledge. 


\subsection{Unexpected results}

An important finding was that none of the literature reviewed for this study mentions the aspect of the nurse practitioner relationship with the patient and the clinical context. Only nurses' beliefs were identified as attributes. This relationship with the patient, as mentioned by Phaneuf $(2008$, pp. 5, 9) and Tanner (2006a, p. 100) is of the outmost importance for engagement with the patient and the family which will allow observation and assessment. Effective clinical judgement thus rests on engaging with the patient and the knowledge of his pattern of responses. It can therefore be listed as a shortcoming of the theoretical definition formulated in this research (Alfaro-LeFevre, 2012, p. 130; Gotlieb, 2013, pp. 37, 205; Higgs et al., 2008, p. 12, 2006b:206; Masters, 2005, pp. 70, 64, 65).

In the next section the study limitations are described, recommendations are made for practice, education and further research, and a summary of the research study is made.

\subsection{Limitations of the research study}

- Due to the limitation of space, the literature review was performed on studies conducted between 1980 and 2013, and only 34 definitions (50 characteristics) were selected which could be limited and more uses could add richness to the identified attributes and the theoretical definition.

- Use of Wikipedia as an encyclopaedic resource may be seen as a limitation, but the fact that it validated and further enriched the identified characteristics of clinical judgement justified its inclusion in the concept analysis process.

- A further finding was that none of the uses/definitions of clinical judgement reviewed for this study mentioned the aspect of nurse-practitioner relationship and engagement with the patient and the clinical context. This relationship and engagement are of the outmost importance in order to be able to observe and assess the patient. It can therefore be listed as a shortcoming of the theoretical definition formulated from this research.

\subsection{Implications for practice, education and research}

\subsubsection{Nursing practice}

In-service education should be established in all clinical nursing environments and in every healthcare institution. The increased knowledge on clinical judgement and its characteristics should enable nurse practitioners to apply clinical judgement as a problem-solving skill that improves patient care and service delivery.

\subsubsection{Nursing education research}

The findings of this study can be used to educate nursing students on the cyclical cognitive thought process which includes clinical reasoning, critical thinking, problem solving and clinical decision-making.

More research should be conducted on teaching/learning strategies for educational preparation of undergraduate nursing students in the cognitive shortcuts and thinking strategies that expert nurses use in order to promote the use of clinical judgement.

\section{Conclusion}

Clarifying the concept of clinical judgement within the clinical nursing environment is not easy because of the multiple facets of the concept within the clinical nursing environment. The method of concept analysis offers a substantial contribution to continuing productive activity in this regard. Through further triangulation of data, nursing education may be able to develop a strong conceptual foundation to enhance efforts towards the continuing development of knowledge in nursing and the achievement of its goals.

The concept of clinical judgement is a very important skill in the clinical decision-making process and can improve nursing care delivery in South Africa. With this article the author provides an overview of the concept of clinical judgement by promoting an understanding of it which will enable nurse educators to develop a teaching/learning strategy which will help nursing students to develop their skills in nursing care and provide autonomous and accountable nursing care.

\section{R E F E R E N C E S}

Aiken, L. H., Clarke, S. P., Cheung, R. B., Sloane, D. M., \& Silber, J. H. (2003). Education levels of hospital nurses and patient mortality. Journal of the American Medical Association, 290(12), 1617-1623.

Alfaro-LeFevre, R. (2012). Critical thinking, clinical reasoning, and clinical judgment: A practical approach (5th ed.). St. Louis, MO: Saunders Elsevier.

ANC (African National Congress). (1994). A national health plan for South Africa. Johannesburg: ANC.

Armstrong, S. J., Geyer, N., Mngomezulu, T. J., Potgieter, E., \& Subedar, H. (2008). In W. Kotze (Ed.), Nurse educator's guide to management. Pretoria: Van Schaik.

Babbie, E., \& Mouton, J. (2005). The practice of social research. Cape Town: Oxford University Press.

Bandman, E. L., \& Bandman, B. (1988). Critical thinking in nursing. New Jersey: Prentice Hall.

Benner, P. (1997). A dialogue between virtue ethics and care ethics. In D. Thomas (Ed.), The moral philosophy of Edmund Pellegrino (pp. 47-61). Dordrecht, Netherlands: Kluwer.

Benner, P., Hooper-Kyriakidis, P., \& Stannard, D. (1999). Clinical wisdom and interventions in critical care: A thinking-in-action approach. Philadelphia: Saunders.

Benner, P., Tanner, C., \& Chesla, C. (1992). From beginner to expert: gaining a differentiated clinical world in critical care nursing. Advances in Nursing Science, 14, 13-28.

Benner, P., Tanner, C., \& Chesla, C. (2009). Expertise in nursing practice: Caring, clinical judgment and ethics (2nd ed.). New York: Springer.

Bitter, N., \& Tobin, E. (1998). Critical thinking: strategies for clinical practice. Journal for Nurses in Professional Development, 14(6), 267-272.

Botes, A. C. (1995). A model for research in nursing. Johannesburg: RAU.

Botes, A. (2003). Validity, reliability and trustworthiness to sum up. In D. Rossouw (Ed.), Intellectual tools: Skills for the human sciences (2nd ed., pp. 176-184). Pretoria: Van Schaik. 
Bright, D., Walker, W., \& Bion, J. (2004). Clinical review: outreach a strategy for improving the care of the acutely ill hospitalized patient. Critical Care, 8(1), 33-40.

Buchan, J., \& Calman, L. (2004). The global shortage of registered nurses: An overview of issues and actions. Retrieved from http:// www.icn.ch/global/summary.pdf.

Burns, N., \& Grove, S. K. (2005). The practice of nursing research: Conduct, critique, and utilization (5th ed.). Missouri: Elsevier Saunders.

Burns, N., \& Grove, S. K. (2009). The practice of nursing research: Appraisal, synthesis, and generation of evidence (6th ed.). Missouri: Elsevier Saunders.

Cotton, A. H. (2001). Private thoughts in public spheres: issues in reflection and reflective practices in nursing. Journal of Advanced Nursing, 36, 512-519.

Creswell, J. W. (2005). Educational research: Planning, conducting and evaluating quantitative and qualitative research (2nd ed.). Upper Saddle River, NJ: Pearson, Merrill Prentice Hall.

Dewey, J. (1987). Experience and nature. Chicago: Open Court Press.

Ebright, P. R., Patterson, E. S., Chalko, B. A., \& Render, M. L. (2003). Understanding the complexity of registered nurse work in acute care settings. Journal of Nursing Administration, 33, 630-638.

Edwards, I., Jones, M., Higgs, J., Trede, F., \& Jensen, G. (2004). What is collaborative reasoning? Advances in physiotherapy, 6, 70-83. In Smith, Higgs and Ellis, retrieved from Trede Jensen http:// www.elsevierhealth.com/media/us/samplechapters/ 9780750688857/9780750688857.pdf. p.89-100.

Facione, N. C., \& Facione, P. A. (2006). The cognitive structuring of patient delay in breast cancer. Social Science and Medicine, 63(12), 3137-3149.

Facione, N. C., \& Facione, P. A.. (2008b). California Academic Press: Millbrae CA. pp. 1-13. Hermosa Beach, CA.

Fish, D., \& Twinn, S. (1997). Quality clinical supervision in the health care professions: Principled approaches to practice. Oxford: Butterworth Heinemann.

Fonteyn, M. E. (1991). Implications of clinical reasoning studies for critical care nursing. Focus on Critical Care, 18(4), 322-327.

Frith, K. H., \& Clark, D. J. (Eds.). (2013). Distance education in nursing (3rd ed.). New York: Springer.

Furguson, L. M. (2006). A grounded theory study of the new nurse's journey toward competence in clinical judgement. Retrieved from http://nwulib.nwu.ac.za/login?url=http://search. Ebscohost. $\mathrm{com} /$ login. aspx? direct $=$ true $\& \mathrm{db}=\mathrm{c} 8 \mathrm{~h} \& \mathrm{AN}=2009711876$.

Geyer, N., Naude, S., \& Sithole, G. (2002). Legislative issues impacting on the practice of the South African nurse practitioner. Journal of the American Academy of Nurse Practitioners, 14(1), 11-15.

Gotlieb, L. N. (2013). Strengths-based nursing care. New York: Springer.

Hammond, K. R. (1996a). Reviewing intuitive decision making and uncertainty: the implications for medical education. Medical Education, 36(3), 216-234.

Hammond, K. R. (1996b). Judgement and social policy: Irreducible uncertainty, inevitable error, unavoidable justice. London: Oxford University Press.

Henderson, V. (1966). The nature of nursing. New York: Macmillan.

Higgs, J., Jones, M. A., Loftus, S., \& Christen, N. (2008). Clinical reasoning in the health professionals (3rd ed.). Butterworth Heinemann, Elsevier.

Hoffman, K. (2007). A comparison of decision-making by "expert" and "novice" nurses in the clinical setting: Monitoring patient haemodynamic status post abdominal aortic aneurism surgery. $\mathrm{PhD}$ thesis. Sydney: University of Technology. Retrieved from https://opus.lib.uts.edu.au/research/bitstream/handle/10453/ 21800/02Whole.pdf? sequence $=2$.

Jooste, K. (2010). The principles and practice of nursing and health care: Ethos and professional practice, management, staff development, and research. Pretoria: Van Schaik.
Klopper, H. C. (1995). Vertrouenswaardigheidstrategieë (Trustworthiness strategies). RAUCUR, 1(1), 25-28.

Klopper, H. C., \& Knobloch, S. (2010). Validity, reliability and trustworthiness. In $\mathrm{K}$. Jooste (Ed.), The principles and practice of nursing and health care (pp. 317-325). Pretoria: Van Schaik.

Knobloch, S. (2007). Compassion fatigue within the nursing profession: A concept analysis. Master's dissertation. Potchefstroom Campus: North-West University.

Krairiksh, M., \& Anthony, M. K. (2001). Benefits and outcomes of staff nurses participation in decision-making. Journal of Nursing Administration, 31(1), 16-23.

Lasater, K. (2007). Clinical judgement development: using simulation to create and assessment rubric. Journal of Nursing Education, 45(11), 496-503.

Laurie, S., Salantera, S., Chalmers, K., Ekman, S. L., Kim, H. S., Kappeli, S., et al. (2001). An exploratory study of clinical decision making in five countries. Journal of Nursing Scholarship, 33(1), 83-90.

Masters, K. (2005). Role development in professional nursing practice. Sudbury, MA: Jones and Bartlett.

Melnyk, B. M., \& Fineout-Overholt, E. (2005). Evidence-based practice in nursing and healthcare: A guide to best practice. New York: Lippincott.

Miller-Keane encyclopaedia and dictionary of medicine, nursing, and allied health (7th ed.). (2003) Retrieved from http://medicaldictionary.thefreedictionary.com/clinical+judgment.

Minick, P., \& Harvey, S. (2003). The early recognition of patient problems among medical-surgical nurses. Medsurg Nursing: Official Journal of the Academy of Medical-Surgical Nurses, 12(5), 291-297.

Mosby's medical dictionary for the health professions and nursing (8th ed.). (2012) Retrieved from http://medical-dictionary. thefreedictionary.com/clinical+judgment.

Mosby's medical, nursing and allied health dictionary (5th ed.). (1998) Retrieved from http://medical-dictionary.thefreedictionary. $\mathrm{com} /$ clinical+judgment.

Moore, G. E. (1983). Some main problems of philosophy. London: Macmillan.

Morse, J. (2003). A review committee's guide for evaluating qualitative proposals. Qualitative Health Research, 13(6), 833-851.

Mouton, J., \& Marais, H. C. (1996). Basiese begrippe: Metodologie van die Geesteswetenskappe. Pretoria: Raad vir Geesteswetenskaplike Navorsing.

Nissen, R. (1884). Sygeplejen (Nursing). Fra Diakonissenhuset et Maanedsskrift, 1(5), 132-133.

Nojima, Y., Tomikwa, T., Makabe, S., \& Snyder, M. (2003). Defining characteristics of expertise in Japanese clinical nursing using the delpi technique. Nursing Health Science, 5, 3-11.

OECD (Organisation for Economic Co-Operation and Development). (2008). Reviews of national policies for education: South Africa. Retrieved from http://www.education.gov.za/ LinkClick.aspx?fileticket=sKsxhYorWOk\% 3D\&tabid $=452 \& \operatorname{mid}=1034$.

Patel, V. L., Kaufman, D. R., \& Magder, S. A. (1996). The acquisition of medical expertise in complex dynamic environments. In Smith, M., Higgs, J. and Ellis, E., 2006, Factors influencing clinical decision making. Doctoral research, Chapter 8: http://www. elsevierhealth.com/media/us/samplechapters/ 9780750688857/9780750688857.pdf. Date of access 10 May 2013. p. 89-100.

Paul, R., \& Elder, L. (2006). The miniature guide to critical thinking: Concepts and tools (4th ed.). Dillon Beach, CA: Foundation for Critical Thinking.

Pelser, A. L., Ngwena, C. J., \& Summerton, L. V. (2004). The HIV/ AIDS epidemic in South Africa: trends, impacts and policy responses. In H. C. J. van Rensburg (Ed.), Health and health care in South Africa (pp. 109-170). Pretoria: Van Schaik. 
Phaneuf, M. (2008). Clinical judgement - An essential tool in the nursing profession. Retrieved from http://www.infiressources. ca/fer/Depotdocument_anglais/Clinical_Judgement \%E2\%80\% 93An_Essential_Tool_in_the_Nursing_Profession.pdf.

Pithers, R. T., \& Soden, S. (2000). Critical thinking in education: a review. Educational Research, 43(3), 237-243.

Polit, D. F., \& Hungler, B. P. (1997). Essentials of nursing research: Methods, appraisal, and utilization (4th ed.). Philadelphia: Lippincott.

RCN (Royal College of Nursing). (2003). Defining nursing. Retrieved from http://www.rcn.org.uk/_data/assets/pdf_file/0008/ 78569/001998.pdf.

SANC (South African Nursing Council). (2013). Geographical distribution of the population of South Africa versus nursing manpower. Retrieved from http://www.sanc.co.za/stats/ stat2013/distribution\%202013.htm.

SAQA (South African Qualifications Authority). (2011). The national qualifications framework: Curriculum development. Retrieved from http://www.saqa.org.za/structure/nqf/docs/curriculum_dev. pdf.

Sari, A. B., Sheldon, T. A., Cracknell, A., Dobson, Y., Grant, C., Gray, W., \& Turnbull, A. (2007). Extent, nature and consequences of adverse events: results of a retrospective case note review in a large NHS hospital. Quality and Safety in Health Care, 16(6), 434-439.

Scheffer, B. K., \& Rubenfeld, M. G. (2000). A consensus statement on critical thinking in nursing. Journal of Nursing Education, 39(8), 352-360.

Shaban, R. (2005). Theories of clinical judgment and decisionmaking: a review of the theoretical literature. Journal of Emergency Primary Health Care, 3, 1-2. article no. 990114.

Simmons, B. (2010). Clinical reasoning: concept analysis. Journal of Advanced Nursing, 66(5), 1151-1158.

Simpson, E., \& Courtney, M. (2002). Critical thinking in nursing education: literature review. International Journal of Nursing Practice, 8(2), 89-98.

Smith, M., Higgs, J., \& Ellis, E. (2006). Factors influencing clinical decision making (Doctoral dissertation, Chapter 8). Retrieved from http://www.elsevierhealth.com/media/us/ samplechapters/9780750688857/9780750688857.pdf.

South Africa. (1996). The constitution of the Republic of South Africa 200 of 1996, as amended. Pretoria: State Press.

South Africa. (2005). Nursing Act 33 of 2005: Regulations relating to performance of community service. Government Notice, No. 765 of 24 August 2005.

South Africa. Department of Health. (2008). Nursing strategy for South Africa, 2008. Retrieved from http://www.info.gov.za/ view/DownloadFileAction?id=105631.

South Africa. Department of Health. (2011). Nursing Act (33/2005): Regulations: approval of and the minimum requirements for the education and training of a nurse leading to registration as a professional nurse. (Notice1046). Government gazette, 34852:20, 14 December 2011.

South Africa. Department of Health. (2013). Nursing strategy for South Africa, http://www.sanc.co.za/archive/archive2013/ NursingStrategy 2013.html. Date of access 03 August 2014.
South African Nursing Council (SANC) 2005, Nursing Act, No 33 of 2005. Pretoria: Government Printers. http://www.sanc.co.za/ pdf/SANC\%20Code\%20of\%20Ethics\%20for\%20Nursing\%20in\%. Date of access 24 May 2014.

Sque, M., Chipulu, M., \& McGonigle, D. (2009). Clinical decision making. In M. Hall, A. Noble, \& S. Smith (Eds.), A foundation for neonatal care: A multi-disciplinary guide (pp. 235-252). Oxford: Radcliffe Publishing.

Standing, M. (2008). Clinical judgement and decision-making in nursing: nine modes of practice in a revised cognitive continuum. Journal of Advanced Nursing, 62(1), 124-134.

Standing, M. (2011). Clinical judgement and decision-making for nursing students. Exeter: Learning Matters.

Sturgeon, D. (2011). Higher education reform: conflict of interest or enhanced experience? British Journal of Nursing, 21(1), 44-47.

Tanner, C. A. (1998). Thinking about critical thinking. Journal of Nursing Education, 32(3), 99-100.

Tanner, C. A. (2006a). The next transformation: clinical education. Journal of Nursing Education, 45(4), 99-100.

Tanner, C. A. (2006b). Thinking like a nurse: a research-based model of clinical judgement in nursing. Journal of Nursing Education, 45(6), 204-211.

Teekman, B. (2000). Exploring reflective thinking in nursing practice. Journal of Advanced Nursing, 31(5), 1125-1135.

Thomas, S. A., Wearing, A. J., \& Bennett, M. J. (1991). Clinical decision-making for nurses and health professionals. Sydney: W.B Saunders/Balliere Tindall. as cited in Smith, M., Higgs, J. and Ellis, E. 2006, Doctoral research, Chapter 8: Retrieved from http://www.elsevierhealth.com/media/us/samplechapters/ 9780750688857/9780750688857.pd.

Thompson, C., Aitken, L., Doran, D., \& Dowding, D. (2013). An agenda for clinical decision making and judgement in nursing research and education. International Journal of Nursing Studies, 50(12), 1720-1726.

Thompson, C., \& Dowding, D. (2002). Clinical decision making and judgement in nursing: London: Churchill Livingstone, 2005. In R. Shaban (Ed.), Journal of Emergency primary health care: 3. Theories of clinical judgment and decision-making: A review of the theoretical literature (1-2), Article no. 990114.

Thompson, C., \& Dowding, D. (Eds.). (2009). Essential decision making and clinical judgement for nurses. Edinburgh: Churchill Livingstone.

Van Rensburg, H. C. J., \& Pelser, A. J. (2004). The transformation of the South African health system. In H. C. J. van Rensburg (Ed.), Health and health care in South Africa (pp. 109-170). Pretoria: Van Schaik.

Walker, L. O., \& Avant, K. C. (2011). Strategies for theory construction in nursing (5th ed.). Boston: Prentice Hall.

Walker, L., \& Gilson, L. (2004). We are bitter but we are satisfied: nurses as street-level bureaucrats in South Africa. Social Science \& Medicine, 59(6), 1251-1261.

Wilson, H. S. (1963). Research in nursing (2nd ed.). Reading, MA: Addison \& Wesley.

Wilson, R. M., Runciman, W. B., Gibberd, R. W., Harrison, B. T., Newby, L., \& Hamilton, J. D. (1995). Quality in Australian health care study. Medical Journal of Australia, 163(9), 458-471. 